\title{
INTEGRATED CHEMIRESISTOR AND WORK FUNCTION MICROSENSOR ARRAY WITH CARBON BLACK/POLYMER COMPOSITE MATERIALS
}
K. Domanský, V. S. Zapf, and J. W. Grate SAND- $-98-1130 \mathrm{C}$
Environmental Molecular Sciences Laboratory, Pacific Northwest National Laboratory Richland, WA 99352 CONF-980638-- JUN 021990
A. J. Ricco and W. G. Yelton
Microsensor R\&D Department
Sandia National Laboratories
Albuquerque, NM 87185-1425

\section{J. Janata}
School of Chemistry and Biochemistry $O S \mathrm{TH}$ Georgia Tech
Atlanta, GA 30332-0400

\begin{abstract}
An array of chemically-sensitive field-effect transistors (CHEMFETs) that measure both work function and bulk resistance changes in thin films was used to detect volatile organic compounds. Carbon black/organic polymer composite films were deposited onto the CHEMFETs using an automated microdispensing method.
\end{abstract}

\section{INTRODUCTION}

Development of hybrid device arrays-those comprised of more than one sensor physical platform type--is an important technology for successful future applications of chemical sensors. Hybrid device arrays offer advantages over traditional sensor arrays because they introduce diversity by measuring different parameters of the sensing layers, as opposed to relying solely on the chemical diversity of the sensing elements. In theory, a low number of chemically diverse costings deposited on different sensor platforms is sufficient to malyze s large number of chemical compounds.

In addition to increasing response information content, it is desirable to integrate different sensor platforms into a single device for cost and space efficiency reasons. We have fabricated chemically-sensitive field-effect transistors (CHEMFETs) which allow resistance and work function (WF) messurements on a single chemically sensitive layer [1]. In the work described here, earbon black/organic polymer composites were used as chemically sensitive coatings on these devices. Although carbon-loaded chemiresistors functioning via vapor-induced swelling have been previously demonstrated $[2,3]$, the purpose of this work is to show the advantages of measuring both WF and electrical resistance.

We also show that composite materials can be successfully deposited onto the tanget sites of CHEMFETs by an automated microdispensing method [4]. In contrast to most traditional thin-film deposition techniques, microdispensing does not have to be combined with photolithographic or other patteming methods, because, typically, nanoliter volumes of materials are deposited only onto selected target locations.

\section{EXPERIMENTAL DETAILS}

The carbon black/polymer composite materials deposited on CHEMFETs are listed in Table 1. Graphitized carbon particles with a $27-30 \mathrm{~nm}$ diameter were used (Polysciences, Inc., Warrington, PA). Each polymer was dissolved in deionized water or toluene to yield a $2 \%$ weighuvolume solution. To promote monodispersion of carbon particles, samples were agitated in an ultrasonic bath for several hours, followed by agitation with a point-source ultrasonic processor, resulting in samples that were kinetically stable for several weeks.

Table 1. Composite films deposited on CHEMFETs.

\begin{tabular}{|l|l|l|l|l|}
\hline $\begin{array}{l}\text { Coating } \\
\text { Code }\end{array}$ & Polymer & $C{ }^{*}$ & Solvent & $\begin{array}{l}\text { Resistivity } \\
{[\Omega-\mathrm{cm}]}\end{array}$ \\
\hline PVA-40-C & $\begin{array}{l}\text { poly(vinyl- } \\
\text { glcohol) }\end{array}$ & 40 & water & $22 \pm 4$ \\
\hline PVA-50-C & $\begin{array}{l}\text { poly(vinyl- } \\
\text { alcohol) }\end{array}$ & 50 & water & $1.0 \pm 0.6$ \\
\hline PVA-60-C & $\begin{array}{l}\text { poly(vinyl- } \\
\text { alcohol) }\end{array}$ & 60 & water & $1.1 \pm 0.3$ \\
\hline PAAS-40-C & $\begin{array}{l}\text { poly(acryl- } \\
\text { amide-acrylic } \\
\text { acid, Na salt) }\end{array}$ & 40 & water & $2.8 \pm 0.8$ \\
\hline EC-40-C & ethyl cellulase & 40 & toluene & $3.1 \pm 0.7$ \\
\hline
\end{tabular}

${ }^{*} \mathrm{CL}$ - carbon losding of the solvent-free composite film, wr\%, 'Measured at $21^{\circ} \mathrm{C}$ and $38 \%$ RH.

Resistivities of the samples deposited on an insulating substrare were calculated from the sheet resistance (4-point probe) and thickness (contact profilometer).

Carbon black/polymer composites were deposited on CHEMFETs using an automated dispensing system (Model A402B, Asymtek, Carlsbad, CA) equipped with AV-500 targeting offset camera and DV-01 syringe valve bracket [4], using 30-Gouge stainless-steel needles. Prior to film deposition, the top $\mathrm{Si}_{3} \mathrm{~N}_{4}$ surface of each CHEMFET chip was etched in buffered HF. The materials were microdispensed as lines $-400 \mu \mathrm{m}$ wide by $600 \mu \mathrm{m}$ long. Typically, less than 30 $\mu \mathrm{L}$ of the solution was sufficient both for the deposition tests on Si wafers and on several CHEMFET chips. On each chip, the same material was deposited on two CHEMFET gares.

The dual-gare CHEMFETs with $\mathrm{SiO}_{2} / \mathrm{Si}_{3} \mathrm{~N}_{\text {, }}$ gate insulators were fabricated at the University of Utah [1]. On both sides of each CHEMFET channel, two parallel Au-plated Pt lines - $165 \mu \mathrm{m}$ apan were formed to allow resistance measurement. Carbon black/polymer composites were deposited onto the $\mathrm{Si}_{3} \mathrm{~N}_{4}$ surface over the channel area $(20 \mathrm{x}$ $400 \mu \mathrm{m}$ ) and on the Au-plated $\mathrm{Pt}$ lines, thereby forming the dual-use transistor gate/chemiresistor films (Fig. 1). Length of the electrode pair in contact with the coating was -500 $\mu \mathrm{m}$. CHEMFET chips with deposited films were artached to 16-pin T0-8 headers and wirebonded. Thickness profiles of carbon black/polymer composites were investigated with a Zygo NewView 200 non-contact profilometer. Headers with mounted CHEMFET chips' were placed in a temperaturecontrolled stainless-steel flow cell [5]. Current-voltage 


\section{DISCLAIMER}

This report was prepared as an account of work sponsored by an agency of the United States Government. Neither the United States Government nor any agency thereof, nor any of their employees, makes any warranty, express or implied, or assumes any legal liability or responsibility for the accuracy, completeness, or usefulness of any information, apparatus, product, or process disclosed, or represents that its use would not infringe privately owned rights. Reference herein to any specific commercial product, process, or service by trade name, trademark, manufacturer, or otherwise does not necessarily constitute or imply its endorsement, recommendation, or favoring by the United States Government or any agency thereof. The views and opinions of authors expressed herein do not necessarily state or reflect those of the United States Government or any agency thereof. 
characteristies of the composite films were measured with a Hewlen-Packard 4142 modular DC Source/Monitor.

An automated vapor-generating/mixing system provided dilutions of isooctane (IOC), acetonitrile (ACN), jsopropyl alcohol (IPA), methyl isobutyl ketone (MIK), and water vapor in nitrogen at a flowrate of 100 sccm. Sensors were exposed for $20 \mathrm{~min}$ esch to six concentrations of each organic vapor, separated by 20 -minute $\mathrm{N}_{2}$ exposures.

Both WF [5] and DC resistance measurements were obtained with mulcichannel instrumentation. WF changes were dectuced by measuring the gate voltage (applied to the coating) necessary to maintain a preset drain-source current. The resistance changes of the films were measured across the width of the coaring with HP 34401 multimeters in twoprobe, constant-current mode ( $500 \mathrm{nA}$ or 5 ㅅ․). Maximum voltage applied to coatings was $-2 \mathrm{~V}$. The data-acquisition sampling period was $10 \mathrm{~s}$. The sensors were maintained above the room temperarure at $35^{\circ} \mathrm{C}$ during all measurements.

\section{RESULTS AND DISCUSSION}

A photograph of a carbon black/polymer composite micradispensed on a CHEMFET chip is showm in Fig. 2a. The composite film overlaps the gate electrodes and completely covers the channel ares, critical for proper device operation. A significant advantage of automated microdispensing is that the deposition is localized, but a drawback is that the thickness uniformity across the film is difficult to control. Fig. 2b. shows a 3-D surface profile of one of the films. The thickness of PVA-60-C is greatest around the perimeter, a source of potential problems for resistance measurements: because the electrodes contact both the thick perimeter section and the thin middle area, the thick edge can adversely affect resistance response time. In contrast, WF response time is not affected because the thick edges are completely outside the transistor channel region. We note that edge effects can be eliminated by burying the electrodes under the perimeter in an electrically insulating film while leaving them exposed in the middle area, where the thickness of the composite material is relatively uniform.

Prior to vapor-exposure experiments, current-voltage characteristics of the composite films on CHEMFETs were messured, and all were found to be ohmic, justifying measurement of resistance changes in constant-current mode. We found resistances measured in $\mathrm{N}_{2}$ and synthetic air to be very similar, indicaring a minimal cffect of oxygen. Comparison of the resistivity values in Table 1 with resistances measured on the coated CHEMFETs suggests that the average thickness of EC-40-C on a CHEMFET is approximately ten times less than that of PAAS-40-C.

When carbon black/polymer composites are exposed to a vapor, analyte molecules can adsorb on the surface of the composite material, absorb in the polymer, adsorb on the surace of carbon particles, and adsorb at the composite material/substrate interface. Vapor-induced polymer swelling and the resulting increase in the average spacing between conductive carbon particles is the predominant response mechanism for the resistance changes $[2,3]$. The effect of the composite materialvapor interaction on the transistor threshold voltage shift $(\Delta \mathbf{V})$ is more complex. We believe $\Delta V_{1}$ is controlled through chemical modulation of the WF by the adsorption of analyte molecules on the surface of carbon particles. However, other effects, such as the analyte-induced change of the polymer dielectric constant, or increased distance of the carbon particles from the $\mathrm{Si}_{3} \mathrm{~N}_{4}$ surface, can also play a role.

Fig. 3 shows the resistance and WF responses of one of the composite materials, PVA-50-C. upon exposure to acetonitrile vapor. Two differences between the resistance and WF responses are notable. First, the WF response for this particular material and analyre is faster than the rcsistance response, perhaps a consequence of the thicker edge region of the film being probed by the resistance measurement but not by the WF. Second, the WF response is approximately logarithmic while the resistance response is linear. This trend is more clear in Fig. 4. which shows the response of PVA-50-C for acetonitrile as well as four other vapors. The linearity of the resistance effect is suggestive of a linear relationship between dissolved analyte and vapor concentrations, coupled with a linear dependence of resistance upon polymer swelling (over the range of concentrations examined). The logarithmic concentration dependence of the WF is likely a consequence of the dependence of the change in carbon-particle surface WF upon the number of adsorbate molecules, convoluted with the adsorption isotherm for the adsorbate on carbon particles.

The effect of carbon loading on the relative change of resistance for PVA is illustrated in Fig. 5. Since the resistance varies approximately linearly with concentration, each point represents a slope. The sensitivity for isooctane (a very nonpolar analyte) is independent of carbon loading, but for waber and acetonitrile (the most polar, highest dielectric analytes). the sensitivity decreases with increasing carbon loading, while for isopropyl alcohol and methyl isobutyl ketone (moderare polarity/dielectric constant), the sensitivity increases. This interesting fearure could be exploired to increase selectivity.

Figs. 6 and 7 show the resistance and WF response patterns of all five tested composite materials to five vapors. Resistance responses are either zero or positive, consistent with vapor-induced swelling. WF responses are mostly ncgative, consistent with the analytes being net electron donors to the carbon paricles. For PVA, the responses decrease with increasing carbon loading for all vapors with the exception of isooctane.

\section{CONCLUSIONS}

The hybrid sensor array resolves all of the vapors at each of several coneentrations reasonably well, which would not be possible using only the resistance or WF response alone. This demonstrates the advantage of the dual-mode measurement platform. Detail data analysis is necessary to quantitatively evaluate discrimination among vapors.

Work at PNNL. SNL. and GaTech was supported by the U.S. DOE Office of National Security and Nonproliferation. Sandia is a mulriprogram laboratory operated by Sandia Corporation, a Lockheed Martin Company, for the United States Department of Energy under Contract DE-ACO4 94AL85000.

\section{REFERENCES}

1. M. Liess, D. Chinn, D. Petelenz, and J. Janara, "Properties of Insulated Gate Field-Effect Transistor with a Polyaniline Gate Electrode", Thin Solid Films, 286, 252 (1996). 
2. B. Lundberg and B. Sundquist, "Resistivity of a Composite Conducting Polymer as a Function of Temperature, Pressure, and Environment: Applications as a Pressure and Gas Concentration Transducer", J. Appl. Phys., 60, 1074 (1985).

3. M. C. Lonergan, E. J. Severin, B. J. Doleman, S. A. Beaber, R. H. Grubbs, and N. S. Lewis, "Array-Based Vapor Sensing using Chemically Sensitive, Carbon Black-Polymer Resistors" Chem. Mater. 8. 2298 (1996).

4. K. Domansky and E. A. Watters. "A Technique for Deposiring Sensing Layers in Integrated Microsensor Arrays by Automated Fluid Dispensing", Proceedings of the Third International Symposium on Microstructures and Mierofabrieared Syslems, Electrochemical Proceedings Volume 97.5, The Electrochemical Society, Pennington (1997), pp. 144-151.

5. K. Domansky. D. L. Baldwin, J. W. Grate, T. B. Hall, J. Li. M. Josowicz, and J. Janats, "Development and Calibration of Field-Effect Transistor-Based Sensor Array for Measurement of Hydrogen and Ammonia Gas Mixrures in Humid Air", Anal. Chem., 70, 473 (1998).

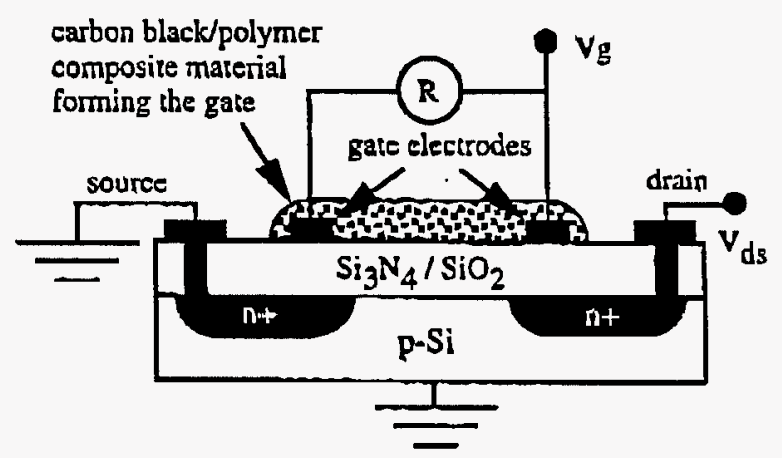

Fig. 1 Device cross seetion.
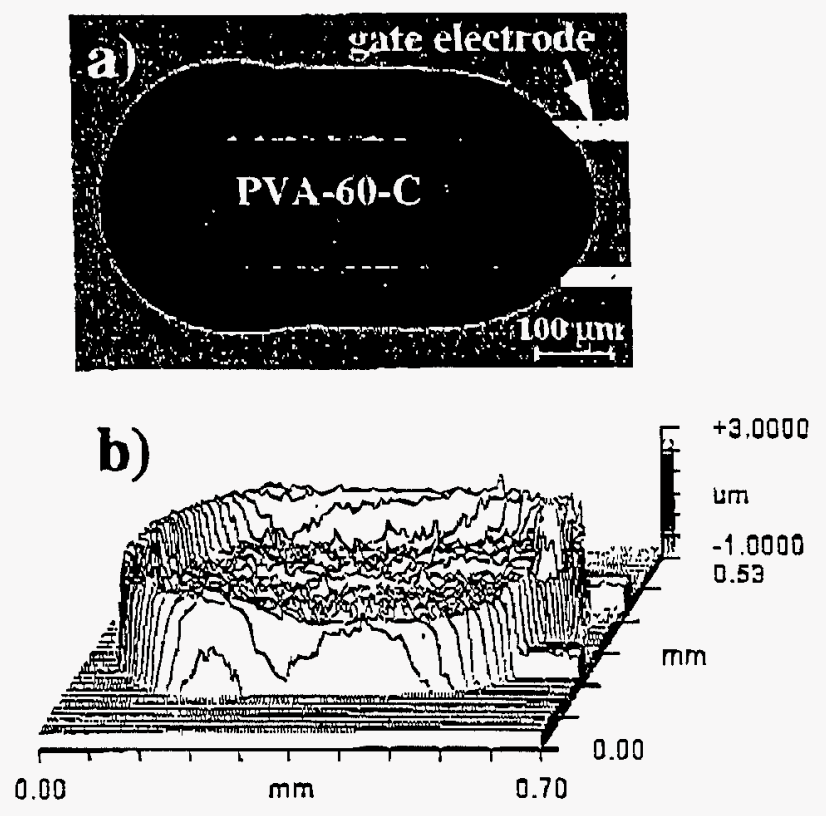

Figure 2. PVA-60-C microdispensed on a CHEMFET chip. a) Photograph of a gatc. b) 3D surface profile of the same gate determined by non-contact profilometry.

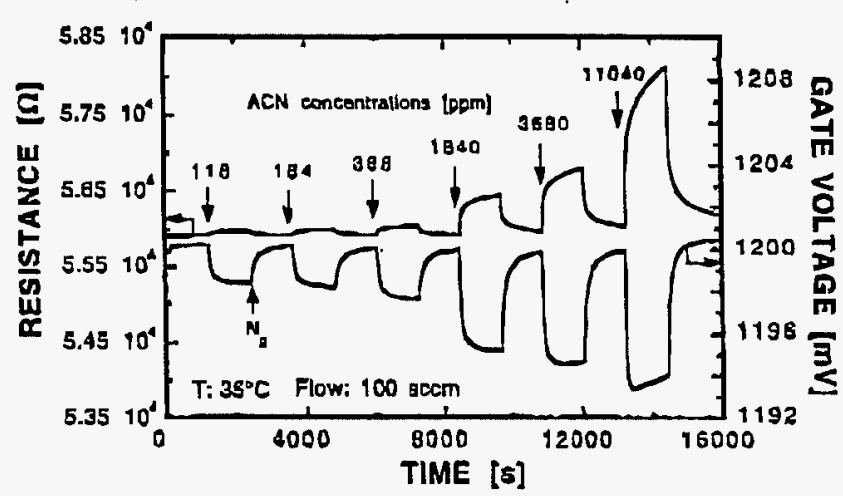

Figure 3. Resistance and work function responses of PVA-50-C to acetonitrile.

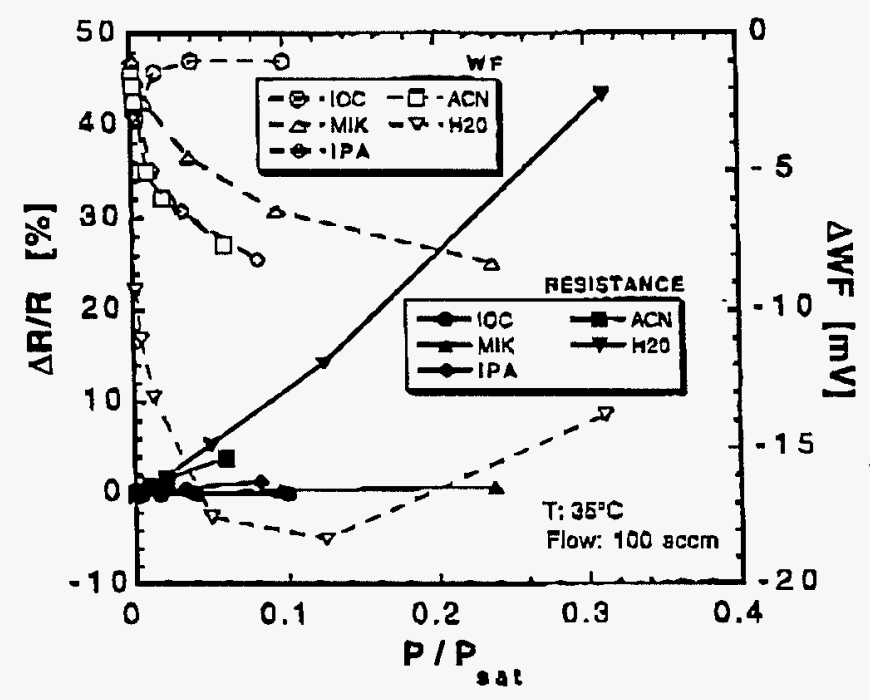

Figure 4, Calibration curves of PVA-50-C for isooctane, methyl isobutyl ketone, isopropyl alcohol, acetonitrile, and water.

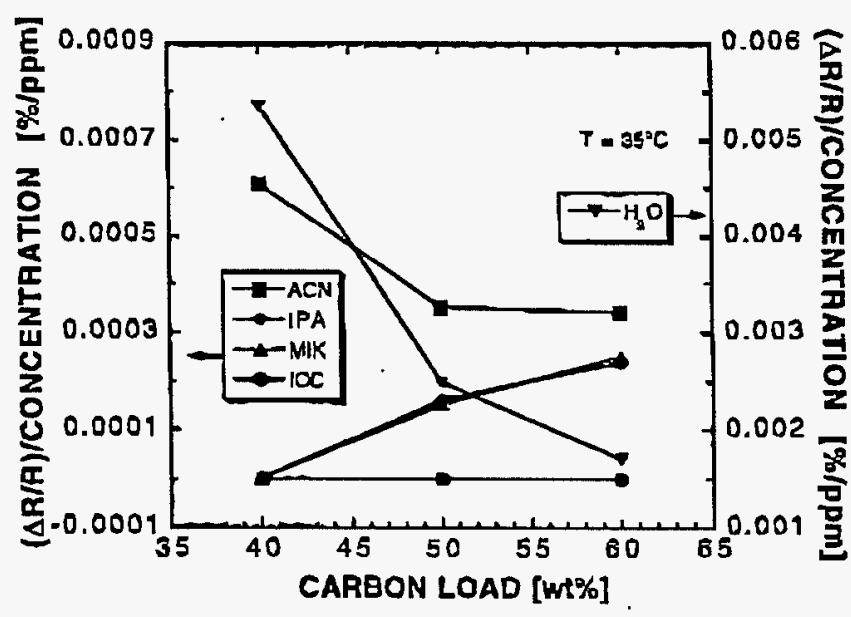

Figure 5. The effect of carbon load on the relative change of resistance for poly(vinyl alcohol). 

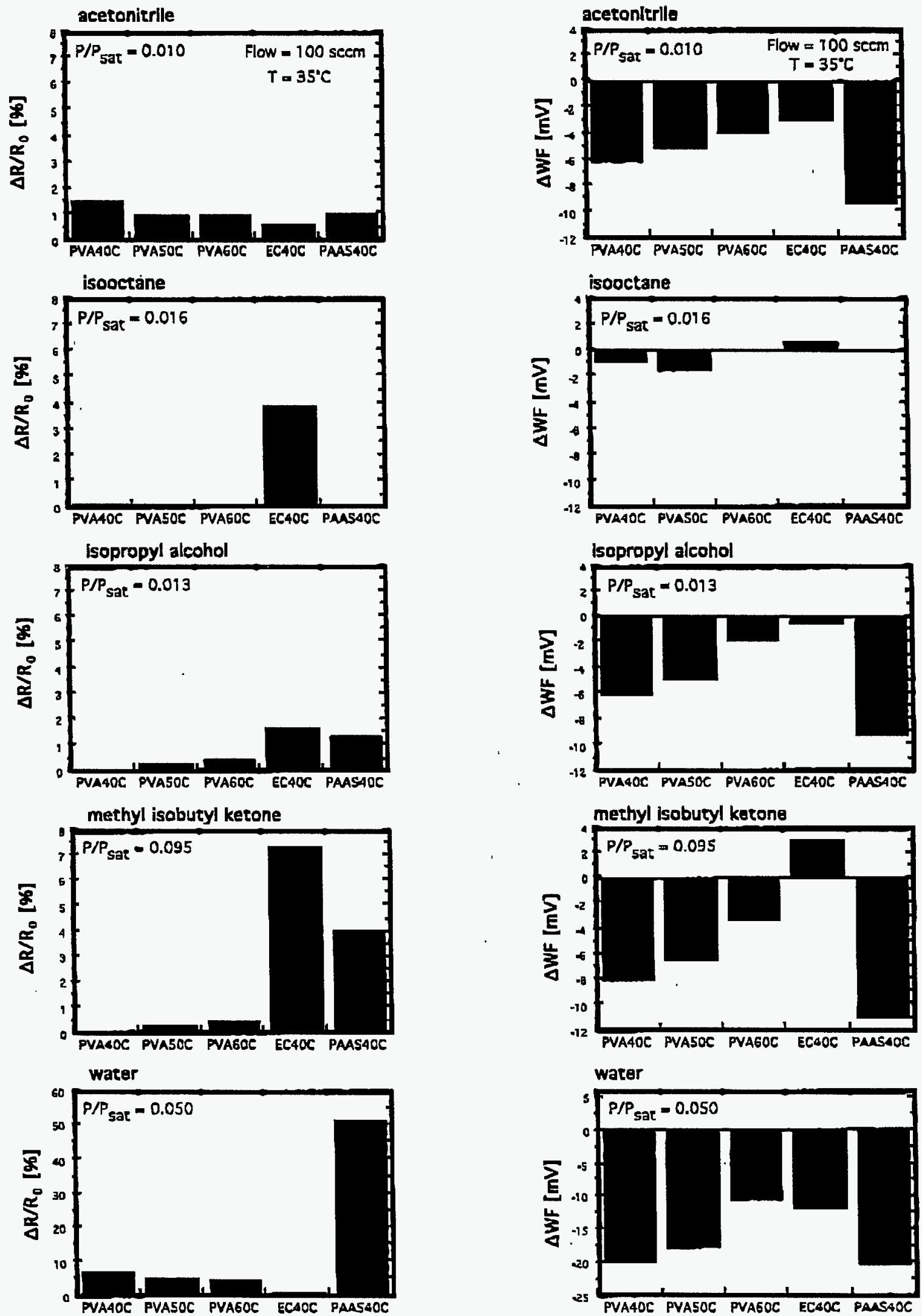

Noise: $\begin{array}{llllll}3000 & 50 & 10 & 100 & 25 & {[\Omega, \mathrm{pp}]}\end{array}$

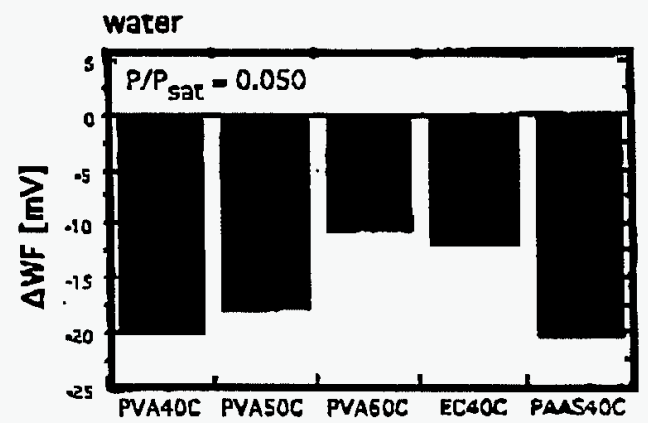

Noise: $\begin{array}{lllllll}0.25 & 0.1 & 0.1 & 0.1 & 1 & {[\mathrm{mV}, \mathrm{pp}]}\end{array}$

Figure 6. Resistance response patterns

Figure 7. Work function response pattems 
M98005464

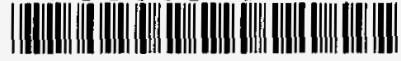

Report Number (14) SAND - $98-1130 C$

CONF-980638--

Publ. Date (11)

199805

Sponsor Code (18) DOE/NN, XF

UC Category (19) $\overline{U C}-900, D O E / E R$

\section{7}

